\title{
Social Media Learning Platforms (SMLPs) As A Performance Enhancer Among Senior Secondary School Science Students.
}

\author{
Ajayi, Peter Oladeji \\ Department of Science Education, Faculty \\ of Education, Ekiti State University, Ado-Ekiti \\ Ajayi, Lois Folasayo \\ Department of Science Education, Faculty \\ of Education, Ekiti State University, Ado-Ekiti
}

\begin{abstract}
The study examined the effects of Social Media Learning Platforms (SMLPs) on secondary school students' performance in Science in Nigeria. It also investigated the rate of use of social media for the purpose of education or otherwise among science students in Secondary schools in Nigeria. The study was a quasi-experimental of pre-test, posttest research design. The sample for the study was 80 Senior Secondary School two students, selected from two schools in Ondo state, South West, Nigeria. Purposive sampling technique was adopted in the selection of the schools and classes for the study. The choice of the sampling technique used was to ensure that the schools and classes selected have access to cell phones and internet facilities during school period and that the classes are science based. The instruments used for the study were Social Media Students Participation Rating Scale (SMSPRS), Social Media Students' Performance Test in Science (SMSPTS), Social Media Students' Questionnaire (SMSQ). Validity and Reliability of the instruments were ensured and determined. Data collated were analyzed using frequency count, mean, standard deviation and t-test. The outcome of the analysis revealed that $98 \%$ of the students' sampled do not use social media for educative learning purposes but for entertainment and socialization. Students exposed to the use of social media platform with conventional teaching-learning method participated better in lessons and performs better in the subject than their counterparts with no use of social media platform.
\end{abstract}

Keywords: Social Media, Participation, Performance, Assignments, Students, Sciences

\section{INTRODUCTION}

The use of social media in Education provides students the ability to retrieve useful information connect with other learning groups and access the global e- system that make Education and learning more meaningful. Social Media Learning Platforms (SMLP) affords students and 
Ajayi, P. O., \& Ajayi, L. F. (2020) Social Media Learning Platforms (SMLPs) As A Performance Enhancer Among Senior Secondary School Science Students. Advances in Social Sciences Research Journal, 7(5) 405-411.

institutions the opportunities of improving learning methods. It serves as a primary source of information to users (Kamau, 2017).

The growth of social media is unprecedented (Lenhart, Parcell, smith and Zickuhr, 2010). Social media technology is now an essential part of personal life mostly among students. They use it in generating content, share photos, videos and play games. It occupies a large portion of students' daily activities. they engage in the use of social media technology both day and night.

Most secondary schools in Africa placed a ban on the use of social media during school time with the purpose of keeping their students' focused on academic activities. But outside school the students are at liberty to stay glued to their cell phones surfing the net for the rest of the day. Some continues on networking activities all night without any meaningful academic attainment. Mageto (2017) and Ngonso (2019) observed that students use social media most often and more than adults. They stayed all day surfing the net at the expense of other essential assignments. On this premise, the study is out to investigate whether converting social media networks to mobile classroom would enhance students' participation and performance in their study areas.

A Social Networking Site (SNS) or social website can be described as a site where people are connected, communicating, socializing, entertaining and sharing contents with others (Babu, 2015). Many researchers have seen social networking activities as time consumer and waster if such activities are not converted to useful academic pursuit (Banu, 2015; Mageto, 2017 and Ngonso, 2019). Such social networking might become a threat to the attainment of nations' educational objectives. SNS is a closed environment where members communicate with each other. This environment could be transformed to academic learning environment which could be suitably used as "distance-learning", "e-learning" and "virtual classroom" and "point-in-time" mobile classroom.

There are several social media networking sites being used by students globally. These include Beboin United Kingdom and Cyworld in Korea. The most popular and global social network services being used include Facebook, Google+, LinkedIn, WhatsApp, Instagram, Reddit, Orkut, MYspace Vine and many more. In Nigeria, those that are commonly used include: WhatsApp, Twitter, YouTube, Google+, Facebook, Telegram, Instagram and Skype (Banu, 2015; Kamau 2017; Ngonso, 2019). All these sites could be converted into a productive learning environment with the aim of enhancing students' participation and performance in their course of study.

Science subjects are practical oriented subjects that involve series of activities and manipulations. There is need for every student to be constant and consistent in studying and practicing such subjects. For effective studying of the subjects, the use of social media networking could be of great. Home assignments could be made available and carried out by the students without any hindrance. The use of social media in Science would also enable both the teacher and his students to take the classroom everywhere they go.

SMLPs are online classrooms running on social media networks that allow video and audio conferencing, screen sharing, two way communications and manipulations. Such social media network applications include: Facebook, WhatsApp, Zoom, Google classroom, Google Docs, Google forms, AZ Recorder, Cisco Web Ex, Team Viewer, Join.Me, Messenger, Apache, Open Meeting, Google Hangouts, GoToMeeting, Skype, Mikogo, WeChat, Screenleap, AnyMeeting, Discord, JitsiMeet, 
Proficonf, UberConference, Whereby and some others that can only be shared through remote access online. The most commonly used Social Media Network in Nigeria includes: Facebook, WhatsApp, Skype, Messenger, Zoom, Google Classroom, Team Viewer and CiscoWeb Ex.

SMLPs in this study comprise only the use of Facebook group class, WhatsApp and Zoom as the mobile classes where all students were registered and interacted together. The Facebook group class, WhatsApp group chat and Zoom were preferred because of their flexibility and long duration of use. They allow two way communications. Facebook has features like "Live Video" which was very good for practical demonstrations during the class. It also has other tools like "Photos", "Events", "Files", "Albums", "Announcements" and "Watch Party". All these are essential tools in the Social Media Learning Platform class. WhatsApp is similar to Facebook because it also allows live video chat but cannot connect above four users at a time on video. Zoom was added to the SMLPs because of its Live Video capability and conferencing. In Zoom, Audio and Video modes could be regulated by the on/off button introduced to it.

Science concepts could be converted to games, simulations and animations which are compatible with the social media platforms. Texts; audio, video clips could be developed and uploaded as part of the learning materials. Teacher's instructions could be broadcast to his students through the social media platforms. Perfect teacher-students interactions can be easily carried out through the platform any time and anywhere. All students are encouraged to participate in the learning process through the use of Social Media Learning Platforms and share ideas among themselves. This would make each student an active member of the class. The use SMLPs would also eliminate "face-to-face" phobia as some learners are shy and fearful during lesson which might turn such one to be inactive during class. Through the use of these platforms, individual differences would be acknowledged and properly handled.

\section{STATEMENT OF THE PROBLEM}

Most students in Senior Secondary Schools (SSS) in Nigeria are used to social media platforms in surfing the net, do other social networking activities like chatting with friends, watching videos and play games. Most of these activities turned to be a mere waste of time. Some of the students are already addicted to the use of social media network at the expense of their academic and career goals. Most of such addicted students often ended to a dropped out of school. The academic culture expected of students is already being eroded as they spend their days and several hours of the night surfing the net and deeply engaging in social activities. This could in turn affect their participation and performance in Science.

The researcher was of the opinion that if most of the time spent by students in surfing the net for socialization could be converted to mobile classroom hours where assignments and study contents are mandatorily given to them, there could be an improvement in the learning outcomes. This study therefore was out to investigate the effects of Social Media Learning Platforms on secondary school students' participation and performance in Science.

\section{Research Questions}

1. Which type of the social media devices are commonly used by students for social networking?

2. Which of the social media network platforms are commonly used by students? 
Ajayi, P. O., \& Ajayi, L. F. (2020) Social Media Learning Platforms (SMLPs) As A Performance Enhancer Among Senior Secondary School Science Students. Advances in Social Sciences Research Journal, 7(5) 405-411.

3. What percentage of students are using social media networks for educative purposes?

\section{Research Hypotheses}

1. There is no significant difference in the level of participation of students in experimental group (social media group) and those in control group

2. There is no significant difference in the performance of students in experimental and control groups

\section{METHODOLOGY}

The design used in this study was a pretest-posttest control quasi-experimental research. The sample used was 80 Senior Secondary School two students offering the three Science subjects. They were selected from two Senior Secondary Schools in Ondo state, South West, Nigeria. Purposive sampling technique was adopted in the selection to ensure that the schools chosen were those that allow their students to hold and use cell phones during school period. The instruments used for the study were Social Media Students' Participation Rating Scale (SMSPRS), Social Media Students' Questionnaire (SMSQ) and Social Media Students' Performance Test in Science (SMSPTS). The SMSPRS was a 10 item self-constructed rating scale. Each item in SMSPRS was rated 2 marks (No participation, NP=0; Partial Participation, PP,=1; Full Participation, FP=2) and for a period of five lessons giving a maximum score of 10 marks per item for the period of the experiment.

SMSPRTS was a 20 item test extracted from the External examination's (WAEC) past questions covering the content taught in this study. Each correct response was awarded 1mark giving a maximum score of 20 marks. SMSQ was a 10 item questionnaire in which 1mark was allocated to each positive response giving a total of 10 marks. Item analysis was carried out on the three instruments to eliminate ambiguous and misleading items. This finally reduced the items in SMSPRS, SMSPTS and SMSQ to 10, 20 and 10 respectively. Face, content and construct validity of the three instruments were ensured. The construct validities of the three instruments were determined by administering them on 10 students outside the sample chosen. The data collected was subjected to statistical analysis using Crombach Alpha Statistics at 0.05 level of significance. The values obtained for SMSPRS, SMSPTS and SMSQ were 0.75, 0.89 and 0.81 respectively.

The reliability indexes of the three instruments were determined using the internal consistency method. The instruments were tested among 10 Senior Secondary School two students offering the three science subjects outside the selected sample. The mean scores and standard deviation were obtained. Kuder Richardson Formula $21\left(\mathrm{KR}_{21}\right)$ was used to analyze the data and the reliability coefficient of the instruments were given at $0.85,07.9$ and 0.77 for SMSPRS, SMSPTS and SMSQ respectively, which ascertained that the three instruments were reliable and suitable for the work.

The two groups (Experimental and control) were exposed to pretest using SMSPTS before the treatment. This was followed immediately with the administration of the SMSQ to elicit information about the manner of social media usage among the students.

Experimental group was thereafter exposed to treatment for 5 weeks using SMLPs by their regular teachers who were already trained in the use of the platforms. During the 5 week lessons, SMSPRS was administered to both experimental and control group to rate the level of participation of students in the teaching process. At the end of the fifth week, SMSPTS was re-administered to the 
two groups to elicit posttest scores. Descriptive analysis was used in answering the research questions while the hypotheses were subjected to t-test. Data collated using the instruments were analyzed and the results are presented accordingly.

\section{RESULTS}

Q1: Which type of the social media devices are commonly used by students for social networking?

Table 1: Percentage Analysis of Types of Devices used by Students for Social Networking

\begin{tabular}{|c|c|c|c|}
\hline Device & N & Percent & Cumulative Percent \\
\hline Cell Phone & 68 & 85.0 & 85.0 \\
Tablet & 4 & 5.0 & 90.0 \\
Laptop & 8 & 10.0 & 100.0 \\
\hline
\end{tabular}

Table 1 revealed that a larger percentage (85.0\%) of student sampled uses Cellphones for accessing Social Network while $5.0 \%$ of them uses Tablets and 10.0\% uses Laptops for general Social Media activities

Q2: Which of the social media network platforms are commonly used by students?

Table 2: Percentage Analysis of social media network platforms are commonly used by students

\begin{tabular}{|c|c|c|c|}
\hline Social Media Network Platform & $\mathbf{N}$ & $\mathbf{\%}$ & Rating \\
\hline Facebook & 80 & 100.0 & 1 \\
WhatsApp & 80 & 100.0 & 1 \\
Zoom & 44 & 55.0 & 3 \\
Skype & 8 & 10.0 & 5 \\
Messenger & 42 & 52.5 & 4 \\
others & 5 & 6.3 & 6 \\
\hline
\end{tabular}

Table 2 showed that all students sampled, 100.0\% were using Facebook, the same $100.0 \%$ also uses WhatsApp, 55.0\% uses Zoom, 10.0\% uses Skype while 52.5\% of the students uses Messenger and $6.3 \%$ of the total sample uses other social media network platforms

\section{Q3: What percentage of students are using social media networking for educative purposes?}

Table 3: Percentage Analysis of Students using Social Media Networking for educative purposes

\begin{tabular}{|c|c|c|c|}
\hline Students & N & Percent & Cumulative Percent \\
\hline Using SMNs & 12 & 15.0 & 15.0 \\
Not Using SMNs & 68 & 85.0 & 100.0 \\
\hline
\end{tabular}

Table 3 revealed that only $15.0 \%$ of the sample used was using Social Media Networks for educative purposes while $85.0 \%$ were using the networks for socialization and other activities outside academic. 
Ajayi, P. O., \& Ajayi, L. F. (2020) Social Media Learning Platforms (SMLPs) As A Performance Enhancer Among Senior Secondary School Science Students. Advances in Social Sciences Research Journal, 7(5) 405-411.

\section{HYPOTHESES TESTING}

Ho1: There is no significant difference in the level of participation of students in experimental group (social media group) and those in control group

Table 4: $t$ test Analysis of Participation Mean Scores of Experimental and Control Groups

\begin{tabular}{|c|c|c|c|c|c|c|}
\hline GRP & N & Mean & Std. Deviation & df & T & sig \\
\hline Experimental & 40 & 8.72 & 0.75 & 78 & 16.95 & 0.000 \\
\hline Control & 40 & 5.12 & 1.11 & 78 \\
\hline
\end{tabular}

From table 4, it showed that P-value (0.000) is less than $\alpha$-value (0.05). Therefore, the hypothesis was rejected. This indicates that there was a significant difference in the lesson participation of the experimental and control groups. Experimental group had a better lesson participation than the control group.

\section{Ho2: There is no significant difference in the performance of students in experimental and control groups}

Table 5: t test Analysis of Performance Mean Scores of Experimental and Control Groups

\begin{tabular}{|c|c|c|c|c|c|c|}
\hline GRP & $\mathbf{N}$ & Mean & Std. Deviation & df & T & sig \\
\cline { 1 - 5 } Experimental & 40 & 14.25 & 2.02 & 78 & 9.6 & 0.000 \\
\hline Control & 40 & 10.20 & 1.72 & 78 \\
\hline
\end{tabular}

Table 5 showed that P-value $(0.000)$ is less than $\alpha$-value $(0.05)$. therefore, the hypothesis was rejected. This implies that there was a significant difference between the performance mean scores of the experimental and control groups. Experimental group performs better than the control group.

\section{DISCUSSION}

The findings of the study revealed that most students use cell phones for their social media networking activities. This made it possible for them to constantly surf the net everywhere they go and any time of the day. The findings revealed further that all students sampled are used to Facebook and WhatsApp networking for their social media activities. They keep themselves busy on Facebook friendship and WhatsApp chatting. This was in agreement with Mageto (2017), Kamau (2017) and Ngonso (2019) who all discovered that most students in Africa stay glued to cell phones for Social activities

The findings further showed that there was a significant difference between the participation of students in experimental and students in control group who were exposed to the use of social media platform in enhancing teaching-learning process participated better in Science lessons than the students who were taught without the use of social media platform. The finding was in agreement with Rdouan, Abdellatif \& Raddouane (2013) who discovered that students participate and communicate better in Education while using social media platform. Meanwhile the finding negates the assertion of Agwi \& Ogwueleka (2018) who said use of social media by students do waste their study time. 
The findings showed that there was a significant difference in the performance of students exposed to the use of social media for teaching-learning and those not so exposed. Experimental group who was exposed to the use of social media platform for teaching-learning perform better in the Sciences than those not exposed. The finding was in agreement with Rdouan, Abdellatif \& Raddouane (2013) and Raymond \& Afua (2016) who all found that use of social media platform enhances students learning outcomes.

\section{CONCLUSION AND RECOMMENDATION}

It was concluded from the study that the use of social media alongside the other conventional methods in teaching Sciences enhances the Students' participation in lessons and their performance in the subject.

It was therefore recommended that Science teachers should use the advantage of available social media platform in students' cell phones and other internet facilities to enhance the students' participation and performance.

\section{References}

Agwi U. C. \& Ogwueleka F. N. (2018). Impact of Social media on students' academic performance. International Journal of Scientific and Engineering Research. 9 (3) 1454-1462.

Babu K. J. (2015). Use of social media among media students. A study in Kashmir. International Journal of Communication and Social Research. 3 (2) 44-60

Kamau V. (2017). Social media is the primary source for African youth. https://techmoran.com/2017/02/28

Lenhart A; Purcell K; Smith A \& Zickuhr K. (2010). Social Media and Mobile Internet Use Among Teens and Young Adults. Few Internet \& American Life Project. https://www.scirp.org

Mageto J. (2017). Impact of Social Media on the Youth. https://migrin.com/document

Ngonso B. F. (2019). Effect of Social Media on Teenagers and Youths; A study of Rural Nigerian Teenagers and Youths in Secondary Schools. Global Media Journal. globalmediajournal.com/open-access 2020.

Raymond O. B. \& Afua A. (2016). The Impact of Social Media on Students' Academic Life In Higher Education; Global Journal of Human Social Science; G Linguistic\&Education (16) 4 1-7.

Rdouan F., Abdellatif E. A. \& Raddouane C. (2013). Exploring the Potential Benefits of using Social Media in Education. http://dx.doi.org/10.3991/ijep.v3i4.2836 3(4) 50-53 